\title{
INDUSTRI FILM INDONESIA : MEMBANGUN KESELARASAN EKONOMI MEDIA FILM DAN KUALITAS KONTEN
}

\author{
Euis Komalawati \\ Fakultas Ilmu Sosial dan Manajemen Institut STIAMI \\ Email : e_komalawati@yahoo.com
}

\begin{abstract}
As an appreciation for creative works, the Indonesian Film Festival (FFI) and the Indonesian Film Appreciation (AFI) aimed at giving an award for the best work. The interesting part was the implementation of AFI 2015 emerged several award categories such as Appreciation for the Local Government and Film Criticism Appreciation. This occurred in the midst of concerns about the development of Indonesian film industries which tend to be stagnant. Film communities tried to give fresh ideas and break the film market. This new award can certainly be seen as an effort through the film festival program in spurring the film industries with creative work of educating the nation's children, especially film as a "cultural builder". Film is a cultural construction. In America, the country where the Hollywood film industry is the mecca of film generation, people still debate the cultural influence of Hollywood on social phenomena. Sociologist Norman Denzim said that drinking shows in US films have influenced the misleading romanticism of alcoholism in public consciousness (Vivian, 2008: 160). On the other hand, borrowing Adorno's term, the film has carried the culture industry powerless with market power. Discussing the media industry leads to the film media economy, as the focus of Indonesian filmmakers today. For most producers, awardwinning films at international film festivals are "less meaningful" when they are not in box office positions. This paper proposed to reveal the economic attractiveness of the film media and the quality of Indonesian film content in accordance with the Republic of Indonesia Act. Number 33 of 2009 on Film. It stated that the film has a function: culture; education; entertainment; information; the driving force of creative work; and economy.
\end{abstract}

Keywords : Film Industry, Media Economy, Film

\begin{abstract}
Abstrak
Sebagai ajang apresiasi pada karya kreatif, Festival Film Indonesia (FFI) dan Apresiasi Film Indonesia (AFI) ditujukan untuk memberikan penghargaan bagi karya terbaik anak bangsa. Yang menarik mulai penyelenggaraan AFI tahun 2015 muncul beberapa kategori penghargaan baru, diantaranya Apresiasi Pemerintah Daerah dan Apresiasi Kritik Film. Hal ini hadir di tengah kekhawatiran perkembangan industri film Indonesia yang cenderung stagnan, muncul insan-insan dan komunitas film yang mencoba bangkit dengan ide-ide segar dan mendobrak market. Penghargaan baru ini tentu dapat dilihat sebagai upaya insan film melalui program festival dalam memacu industri film dengan karya kreatif mencerdaskan anak bangsa khususnya film sebagai "pembentuk budaya". Film sebagai konstruksi budaya. Di Amerika, negara di mana industri film Hollywood menjadi kiblat generasi film, masih mendebatkan pengaruh kultural Hollywood pada fenomena sosial. Sosiolog Norman Denzim mengatakan bahwa tayangan minum-
\end{abstract}


minum di film-film AS ikut memengaruhi romantisme menyesatkan tentang alkoholisme dalam kesadaran publik (Vivian, 2008 : 160). Di sisi lain, meminjam istilah Adorno, film telah mengusung industri budaya yang tidak berdaya dengan kuasa pasar. Membahas industri media mengarah pada ekonomi media film, sebagaimana fokus kalangan sineas Indonesia saat ini. Bagi kebanyakan produsen, film yang meraih penghargaan di festival film internasional sekalipun menjadi "kurang berarti" ketika tidak berada di posisi box office. Tulisan ini berupaya mengungkapkan tarik menarik ekonomi media film dan kualitas content film Indonesia sesuai amanat Undang-Undang Republik Indonesia Nomor 33 tahun 2009 tentang Perfilman, bahwa perfilman mempunyai fungsi: budaya; pendidikan; hiburan; informasi; pendorong karya kreatif; dan ekonomi.

Kata kunci : Industri Film, Ekonomi Media, Film

\section{PENDAHULUAN}

Film sebagai media komunikasi massa hingga kini masih bertahan di tengah perkembangan new media yang kian marak dalam berbagai aspek. Film dipandang dalam berbagai perspektif yang berbeda baik sebagai seni, media edukasi, dan industri media massa.

Dalam konteks industri media massa, film merupakan industri budaya yang bergerak dalam logika bisnis yang tidak dapat dilepaskan dari ekonomi media. Ekonomi media akan menggerakkan bisnis film dengan perhitungan profit yang sering kali mengabaikan peran dan posisi film dalam kehidupan bangsa Indonesia. Pentingnya film bagi perjalanan bangsa dituangkan dalam Undang-Undang Perfilman tahun 1992 yang kemudian diperbarui pada Undang-Undang Nomor 33 tahun 2009 yang disesuaikan dengan perkembangan masa.

Dalam UU Perfilman tahun 2009, dinyatakan bahwa bahwa (1) film sebagai karya seni budaya memiliki peran strategis dalam peningkatan ketahanan budaya bangsa dan kesejahteraan masyarakat lahir batin untuk memperkuat ketahanan nasional dan karena itu negara bertanggung jawab memajukan perfilman; (2) bahwa film sebagai media komunikasi massa merupakan sarana pencerdasan kehidupan bangsa, pengembangan potensi diri, pembinaan akhlak mulia, pemajuan kesejahteraan masyarakat, serta wahana promosi Indonesia di dunia internasional, sehingga film dan perfilman Indonesia perlu dikembangkan dan dilindungi; (3) bahwa film dalam era globalisasi dapat menjadi alat penetrasi kebudayaan sehingga perlu dijaga dari pengaruh negatif yang tidak sesuai dengan ideologi Pancasila dan jati diri bangsa Indonesia; dan (4) bahwa upaya memajukan perfilman Indonesia harus sejalan dengan dinamika masyarakat dan kemajuan ilmu pengetahuan dan teknologi ${ }^{1}$

Berdasarkan keempat pertimbangan tersebut, maka negara bertanggung jawab untuk memajukan perfilman termasuk industri kreatif yang sejalan dengan kemajuan ilmu pengetahuan dan teknologi. Namun, film dan perfilman tidak hanya

\footnotetext{
${ }^{1}$ Undang-Undang Nomor 33 tahun 2009 tentang Perfilman.
} 
Euis Komalawati, Industri Film Indonesia :Membangun Keselarasan Ekonomi....

dikembangkan tetapi juga dijaga dan dilindungi dari pengaruh negatif yang tidak sesuai dengan ideologi Pancasila dan jati diri bangsa.

Salah satu upaya pemerintah untuk memadukan kemajuan perfilman dan melindungi pengaruh negatif yaitu dengan mengembangkan festivalfestival film. Dalam Laporan Dialog Perfilman Nasional yang disusun oleh Pusat Pengembangan Film Nasional terekam berbagai permasalahan perfilman nasional. Laporan tersebut menyebutkan bahwa beragam kegiatan festival perfilman diprakarsai oleh berbagai kelompok masyarakat akar rumput, kerap dengan menggunakan dana swadaya yang dimobilisasi sendiri. Berdasarkan data dari asosiasi festival film Indonesia, terdapat sekitar 20 festival film yang aktif diselenggarakan. Laporan tersebut menyebutkan bahwa pada satu sisi, festival film berfungsi menjadi ajang pemberian apresiasi terhadap film-film atau para pekerja budaya yang dianggap memenuhi standar kualitas tertinggi dan di sisi lain festival film diselenggarakan sebagai sebuah moda budaya yang menumbuhkan dan merawat budaya menonton di suatu daerah serta menjaring talenta dan karya lokal, yang kerap terpinggirkan dari wajah sinema Indonesia. Terbukti bahwa dari festivalfestival ini, lahir sineas-sineas muda berpengaruh. Laporan yang disusun berdasarkan Focus Group Discusssion tersebut dilakukan pada 22 Desember 2015 di Jakarta yang menghadirkan sekitar 40 peserta yang mewakili beragam kepentingan: produser film, sutradara, jaringan gedung bioskop, sineas, wartawan, pemerhati, stasiun televisi, lembaga pengarsipan, animasi, pendidik, distributor, pengorganisir dan pengembang festival, publisis, dan kalangan terkait lainnya, ini menyatakan bahwa peran pemerintah dalam penyelenggaraan berbagai festival film seringkali hanya bersifat minimal atau tidak ada sama sekali. Pemerintah lebih terlibat dalam festival film yang berformat pemberian penghargaan di tingkat nasional, seperti Festival Film Indonesia. Pemerintah belum banyak terlibat dalam Festival Film yang berformat penayangan filmfilm berkualitas atau film-film alternatif di tingkat regional dan lokal. ${ }^{2}$

Dua festival film yang diselenggarakan pemerintah yakni Apresiasi Film Indonesia (AFI) dan Festival Film Indonesia (FFI), keduanya diselenggarakan oleh Kementerian Pendidikan dan Kebudayaan. Berbagai penghargaan diberikan pada karyakarya terbaik sineas Indonesia.

AFI tahun 2016 dilaksanakan di Manado Sulawesi Utara pada 8 Oktober 2016. Sedangkan Festival Film Indonesia (FFI) diselenggarakan di Taman Ismail Marzuki, Minggu 6 November 2016. Namun sayang, meskipun gaung kedua festival ini cukup menggema dalam dunia hiburan tanah air, kedua festifal tersebut kurang mendapat apresiasi pada industri

\footnotetext{
${ }^{2}$ Laporan Dialog Perfilman Nasional - "Peta Permasalahan Perfilman Nasional Dan Rekomendasi Program Dan Kebijakan Perfilman Nasional", Pusat Pengembangan Perfilman Indonesia, 2016.
} 
perfilman. Hal ini dapat teramati dari karya-karya yang berhasil meraih penghargaan di ajang festival tersebut, hanya beberapa yang bertahan di industri perfilman. Bahkan yang lebih memprihatinkan banyak kalangan tak memiliki media untuk menikmati karyakarya tersebut karena terbatasnya ruang dan waktu tayang pada bioskop komersil seperti jaringan XXI dan CGV Cinemas.

Fenomena berbeda terjadi pada ajang penghargaan Golden Globe Awards yang digelar Amerika setiap tahunnya, dimana para pemenang selalu dinanti dan film-film peraih penghargaan akan diburu penonton dan bahkan menjadi box office. Aktor dan aktris pemenang Golden Globe selalu dinanti film-film berikutnya. Secara kasat mata nampak adanya keselarasan antara ekonomi media dan film-film yang dinilai berkualitas dan mendapat penghargaan. Memang tidak semua film pemenang award digemari kalangan distribuor film di Hollywood, namun setidaknya film dapat bertahan dan dinikmati di bioskop-bioskop komersil.

Mengacu pada fenomena tersebut, maka permasalahan yang ingin diungkap adalah bagaimana membangun keselarasan ekonomi media dan kualitas konten dalam industri perfilman Indonesia.

\section{TINJAUAN PUSTAKA}

\section{Industri Budaya}

Industri perfilman sebagai industri media massa merupakan industri budaya yang padat modal. Konsep industri budaya telah lama diusung teoretisi kritis yakni Hokheimer dan Adorno.

Pemahaman umum tentang logika pencerahan dan dominasi menjadi latar belakang bagi Hokheimer dan Adorno dalam menganalisa ciri dan konsekuensi industri budaya. Hokheimer dan Adorno menggunakan istilah 'industri budaya' untuk mengacu pada komodifikasi bentuk-bentuk budaya sebagai akibat dari munculnya industri hiburan di Eropa dan Amerika Serikat pada akhir abad sembilan belas dan awal abad dua puluh, diantaranya film, radio, televisi, musik rakyat, majalah, dan surat kabar. ${ }^{3}$

Keduanya berpendapat bahwa munculnya industri hiburan sebagai bentuk perusahaan kapitalistik telah menyebabkan terjadinya standardisasi dan rasionalisasi bentuk-bentuk budaya. Proses ini pada gilirannya mengurangi kemampuan individu untuk berpikir dan bertindak secara kritis dan otonom.

Industri budaya sengaja mengintegrasikan para konsumen dari atas, masyarakat tidak bersifat primer, tetapi sekunder, mereka menjadi objek kalkulasi; sebagai bagian dari cara kerja sebuah mesin. ${ }^{4}$

Barang-barang yang diproduksi oleh industri budaya tidak ditentukan oleh karakter intrinsiknya semisal bentuk seni, tapi oleh logika hukum produksi dan pertukaran komoditas. Karena itu barang-barang itu berstandar dan mengandung stereotype - hanya

\footnotetext{
${ }^{3}$ Max Hokheimer and Theodore W Adorno, "The Culture Industry : Enlightenment as Mass Deception", dalam Dialectic of Enlightenment, hlm. 120-67.

4 Adorno, 'Culture Industry Reconsidered', hlm.
} 12. 
Euis Komalawati, Industri Film Indonesia :Membangun Keselarasan Ekonomi....

sebagai perubahan urutan genre dan bentuk dasar saja ${ }^{5}$.

Dalam karyanya Adorno mengungkapkan bahwa seluruh hasil industri budaya sangat berbeda dengan karya seni tradisional. Pada abad delapan belas dan sebelumnya, karya sastra berusaha mempertahankan otonomi tertentu dari tuntutan pasar, menggunakan sistem langganan yang dapat melindungi sang seniman dari adanya tuntutan hidup yang tiba-tiba. Otonomi ini mengambil jarak dengan realitas yang ada, untuk mengekspresikan penderitaan dan perbedaan dan karena itu tetap dapat mempertahankan nilai dan cita-cita hidup yang mulia. Tapi dengan kemajuan komodifiksi barang-barang budaya, otonomi tersebut menjadi rusak. Seni kemudian menjadi bagian dari logika produksi dan pertukaran komoditas, dan karena itu kehilangan potensi kritisnya yang inheren dalam setiap ketidaksengajaan bentuk-bentuk artistik tradisional $^{6}$.

Kebanyakan produksi industri budaya kurang berhasil menciptakan pretensi karya seni. Hal tersebut disebabkan rata-rata produk itu berupa konstruksi simbol yang dibentuk berdasarkan formula yang dibangun sebelumnya dan diisi dengan stereotype setting, karakter dan tema tertentu. Ia tidak berlawanan dan bertentangan dengan norma sosial yang ada; tapi sebagai penegasan kembali norma itu dan mengecam tindakan dan perilaku yang dianggap menyimpang dari norma

\footnotetext{
${ }^{5}$ Thompson, John B 'Kritik Ideologi Global', 2015, hlm. 136-140

${ }^{6}$ Ibid
}

tersebut. Produksi industri budaya menghadirkan dirinya sebagai refleksi langsung terhadap pengembangan realitas empiris, dan melalui 'pseudorealisme' ini, produk tersebut menormalisasi status quo serta membatasi refleksi kritis terhadap tatanan sosial dan politik. Apa yang masyarakat baca, lihat dan mereka dengar adalah sesuatu yang sudah mereka akrabi dan biasa, dan ke dalam wilayah simbol dari keakraban yang berulang-ulang itu dimasukan sebuah rujukan slogan yang sederhana 'all foreigners are suspect, a pretty girl can do no wrong, succes is the ultimate aim in life - yang seakan-akan sebagai pembuktian diri dan kebenaran yang abadi ${ }^{7}$.

Seluruh produk industri budaya dibentuk untuk menyesuaikan dan mencerminkan suatu realitas sosial yang dikembangkan tanpa dasar kebutuhan eksplisit akan independensi dan kuasiindependen : justifikasi dan pembelaan. Karena itu seluruh proses konsumsi produk industri budaya akan mengarahkan individu untuk melakukan identifikasi terhadap norma sosial yang berlaku serta mengamalkan sebagaimana adanya.

Dalam pandangan Hokheimer dan Adorno, perkembangan industri budaya merupakan bagian intrinsik dari proses meningkatnya rasionalisasi dan konkritisasi (reification) masyarakat modern, sebuah proses yang menjadikan individu lemah dan kurang mampu melakukan cara berpikir bebas dan lebih bergantung pada proses sosial

${ }^{7}$ Ibid, hlm. 139. 
yang berada di luar kontrol mereka. Disinilah pengaruh kuat Max Weber terbukti :'sangkar besi' Weber tentang tindakan yang dirasionalkan dan dibirokratisasikan digantikan oleh 'sistem besi' industri budaya dimana individu dikitari oleh dunia obyek yang secara esensial identik dan sepenuhnya dikomodifikasikan (commodified $)^{8}$.

Kehidupan

yang

dikomodifikasikan ini menyalurkan energi individu ke dalam konsumsi kolektif akan kebutuhan yang sudah ditakar (standardized). Individu disesuaikan dan dibiasakan dengan tatanan sosial yang ada melalui setiap keinginan (desire) terhadap objek-objek yang diproduksi serta melalui kesenangan yang akan mereka nikmati ketika mengkonsumsi obyek tersebut.

\section{Ekonomi Media}

Operasionalisasi media massa membutuhkan biaya mahal. Peralatan dan fasilitas membutuhkan investasi besar. Untuk menutupi biaya ini, media massa menjual produknya dengan dua cara. Mereka memperoleh pendapatan dengan menjual produk langsung ke audiens massa, seperti industri film, rekaman musik, dan buku, atau mereka meraih pendapatan dari pengiklan yang memasang iklan untuk audiens massa yang disediakan oleh media, seperti yang dilakukan koran, majalah, radio, dan televisi ${ }^{9}$.

Ekonomi media terkait dengan (1) Penerimaan Iklan ; para pengiklan membayar media massa agar

\footnotetext{
${ }^{8}$ Ibid, hlm. 136-138.

${ }^{9}$ Vivian, 2008, hlm. 20.
}

mendapatkan akses ke konsumen potensial. Pengiklan membeli ruang media cetak, dan membeli waktu di media siaran. Umumnya semakin potensial konsumen yang dapat diberikan media kepada pengiklan, semakin besar biayanya untuk ruang atau waktu. Film juga memperoleh pendapatan dari iklan. Sampai 1950-an film mengandalkan pada penjual dan tiket untuk meraih keuntungan, namun kini pembuat film bisa menghitung profit apa yang dapat mereka peroleh bukan hanya melalui tiket bioskop, tetapi juga dari penjualan film ke televisi dan pasar home video, (2) Pendapatan Sirkulasi ; yaitu pendapatan yang diperoleh dari audien. Produser rekaman, film, dan penerbit buku banyak tergantung kepada penjualan langsung ke konsumen, (3) Sumbangan Audiens ; donasi audien penting bagi beberapa operasi media. Stasiun radio dan televisi publik, yang tidak menyiarkan iklan, menarik sumbangan dari audiennya. Di Amerika, acara pengumpulan sumbangan, biasanya dilakukan selama empat minggu dalam setahun, biasanya meraup $30 \%$ dari anggaran banyak stasiun. Pendengar dan pemirsa umumnya rela menyumbang karena stasiun itu menekankan bahwa mereka menitikberatkan pada persoalan publik dan isi yang mencerdaskan secara kultural. Isi semacam ini sulit dijumpai di media yang didukung iklan, (4) Dukungan Privat ; dukungan privat atau pihak swasta, yang kebanyakan dari organisasi filantropi dan perusahaan raksasa, (5) Subsidi Pemerintah ; gagasan dukungan pemerintah untuk 
Euis Komalawati, Industri Film Indonesia :Membangun Keselarasan Ekonomi....

media massa mungkin kelihatan bertentangan dengan cita-cita demokrasi pers yang ideal, yakni pers yang bebas dari campur tangan pemerintah, bahkan bersikap kritis terhadapnya. Tetapi, faktanya Kongres memberikan dana \$286 juta dari pendapatan pajak untuk agen semi-pemerintah, Corporation for Public Broadcasting, untuk membantu siaran radio dan televisi nonkomersial milik negara. Di dalamnya dibuat aturan untuk mencegah intervensi pemerintah dalam pembuatan acara, (6) Iklan Pemerintah ; pemerintah AS menggelontorkan banyak uang ke media massa melalui advertising. Pada tahun 2005 pemerintah berada di urutan ke-25 dari daftar pengiklan terbesar, menghabiskan sekitan $\$ 1.3$ miliar $^{10}$.

\section{Ekonomi Media Film}

Industri film Hollywood sebagai barometer industri film dunia menjalankan roda bisnis perfilman sejak awal abad ke-20. Enam perusahaan besar yang menduduki posisi puncak industri film Hollywood yakni Warner Brothers, Columbia, Universal, 20th Century Fox, Paramount, dan Walt Disney. Namun studio besar juga mendapat keuntungan ekonomi dalam memilih film-film yang dibuat oleh produser independen dan mendapat modal dari usaha-usaha pelengkap film.

Aspek ekonomi media film terkait pada hal-hal : (1) Pembiayaan Studio ; pembuatan film menghabiskan anggaran yang besar. Pembiayaan ini berasal dari (a) studio besar - yang membiayai banyak film dengan

\footnotetext{
${ }^{10}$ Ibid, hlm. 22-24.
}

menggunakan laba yang mereka peroleh dari film sebelumnya. Studio besar adalah bagian dari konglomerat yang bisa mengambil dana dari perusahaan induknya; (b) kelompok investor kelompok investor khusus terkadang bergabung untuk mendanai film untuk studio besar; (c) bank - untuk menutup biaya produksi, studio meminjam uang ke bank dengan jaminan aset mereka, seperti fasilitas produksi dan segudang film yang menunggu untuk dirilis ; (2) Produser Independen ; saat ini studio besar mencari produser independen untuk mengambil filmya. Produser independen menunjukkan bahwa studio besar tak punya monopoli atas orisinalitas dan kreativitas; (3) Purna Jual ; ketika pembuat film berencana membuat film, mereka akan menyusun anggaran yang mengantisipasi pendapat di luar pemutaran film di bioskop. Film biasanya dirilis di AS dan luar negeri secara bersamaan. Pendapatan distribusi luar negeri bisa signifikan. Pendapatan box office dari film AS yang diputar di luar negeri bahkan amat penting bagi neraca perdagangan negara. Pendapatan purna pasar berasal dari saluran televisi pay-per-view dan pasar home video; (4) Usaha Pendukung ; studio film punya sumber pendapatan dari kegiatan pendukung atau pelengkap di luar penjualan tiket film, antara lain (a) Merchandise tie-ins : keuntungan dapat diperoleh dengan memberikan lisensi kepada perusahaan lain untuk menggunakan karakter dan item khas dari sebuah film; (b) Mainan : pembuat film mendapat insentif finansial besar sehingga mereka melakukan apa saja untuk meraih kesuksesan. Pembuat 
mainan membayar biaya lisensi, biasanya 10 persen dari harga eceran mainan atau boneka; (c) Musik : tie-ins bukan barang baru. Musik, misalnya adalah salah satu sumber pendapatan dari film. Saat ini, musik memegang peran penting selain mendukung adegan di layar; (d) Placement Product; pembuat film juga mulai membangun produk komersial dalam lini cerita melalui iklan terselubung. Beberapa produser film menempatkan merek ke film mereka dengan memungut biaya ${ }^{11}$.

\section{HASIL PENELITIAN DAN PEMBAHASAN}

Sebagai industri media, film dapat diamati dari aspek ekonomi media film. Tidak seperti Hollywood, industri film Indonesia tidak hanya dikuasai oleh studio-studio besar. Sedikitnya tercatat empat puluh perusahaan produksi film Indonesia. Sebagian besar perusahaanperusahaan tersebut tergabung dalam Persatuan Perusahaan Film Indonesia (PPFI) yang didirikan di Jakarta, sejak 16 Juli 1956. PPFI lahir sebagai wadah perjuangan insan perfilman. Dalam hal ini para produser film ketika itu. Perjuangan PPFI bersama insan perfilman lainnya ketika itu berhasil memperjuangkan pengurangan dominasi film impor. Hal tersebut memberikan ruang yang lebih besar terhadap film produksi Nasional. Disamping itu, PPFI juga membantu penyelenggaraan berbagai festival film di dalam dan luar negeri ${ }^{12}$.

\footnotetext{
${ }^{11}$ Ibid, hlm. $171-177$.

$12 \mathrm{http}: / /$ ppfindonesia.blogspot.co.id/p/tentangkami.html
}

Berikut adalah daftar perusahaan produksi film. Beberapa diantaranya sangat produktif dan sebagian lain tidak lagi produktif menghasilkan karya film. Lihat Tabel 1.

Selain perusahaan produksi film, produksi film juga banyak dihasilkan oleh produser independen. Umumnya produser independen dilakukan oleh komunitas-komunitas independen yang tidak ingin didominasi industri film yang cenderung mengabaikan kualitas konten.

Tidak seperti industri film Hollywood yang senantiasa merilis film baik di dalam maupun luar negeri, film Indonesia belum mampu menembus pasar ekspor. Kendala bahasa, budaya, dan marketing film menghambat pasar ekspor. Beberapa film memang mampu meraih perhatian negara tetangga seperti film Laskar Pelangi dan The Raid, namun sebagian besar lain bahkan terseok-seok dalam kompetisi di dalam negeri.

Ekonomi media film tidak hanya mengandalkan pendapatan dari penjualan tiket, namun juga melalui usaha pendukung berupa penjualan merchandise tie-ins, mainan, musik dan placement produk. Dalam kapasitas yang terbatas, beberapa film telah melakukan usaha pendukung ini meski mendapat kritik baik dari penonton maupun dari kalangan sineas.

Penjualan merchandise tie-ins misalnya dilakukan Haykal Kamil dalam film Perahu Kertas. Ia juga mempunyai kontrak sebagai official merchandise dengan Screenplay 
Euis Komalawati, Industri Film Indonesia :Membangun Keselarasan Ekonomi....

Production yang memproduksi sinetron Love in Paris $2 .^{13}$ Lihat Gambar 1.

Usaha pendukung lainnya yang telah banyak dilakukan dalam industri film Indonesia adalah musik yang kemudian dikenal dengan soundtrack film. Beberapa film bahkan terinspirasi karena musik/lagu tertentu, dan sebagian lain menayangkan film dengan soundtrack film yang dipasarkan film tayang, sehingga dapat turut mempromosikan film. Berikut adalah beberapa soundtrack film yang dinilai populer bahkan setelah filmnya tak lagi tayang di sinema ${ }^{14}$. Lihat Tabel 2.

Usaha lain dilakukan dengan placement product. Pada industri film Hollywood, usaha ini banyak dilakukan kalangan sineas dan bahkan menjadi salah satu momen yang diselaraskan dengan launching suatu produk. Filmfilm James Bond dikenal sebagai film yang senantiasa melakukan placement product untuk beragam produk baik yang dikenakan maupun yang dikonsumsi agen 007.

Industri film Indonesia juga mulai melakukan placement product meski selalu mengundang kritik terkait dengan logika dan rasionalisasi fakta dan setting. Contoh placement product dilakukan dalam film Di Bawah Lindungan Ka'bah (2011), yang menampilkan Kacang Garuda dan wafer Gery Chocolatos $^{15}$. Lihat Gambar 2.

\footnotetext{
${ }^{13}$ http://www.merdeka.com/artis/haykalkamil-juga-jualan-official-merchandiselove-in-paris-2.html

${ }^{14} \mathrm{https} / / / \mathrm{www}$.inovasee.com/soundtrackfilm-indonesia-terbaik-18888/

15 http://www.muvila.com/film/artikel/productplacement-paling-wajar-dalam-film-

1302043-page3.html
}

Selain film di atas, film Habibie \& Ainun yang sukses menarik perhatian sebagai film dengan jumlah penonton terbanyak nomor dua di Indonesia dengan jumlah penonton sebanyak 4.488.889 ${ }^{16}$ juga melakukan placement product $^{17}$. Lihat Gambar 3.

Penempatan produk ini seringkali menuai kritik. Beberapa di antara pengkritik meminta agar praktek ini dilarang, namun sebagian yang lain mengatakan bahwa kata "advertisement" harus dimunculkan di layar saat produk itu muncul.

Dalam beberapa referensi mengungkapkan jenis komersialisasi ini melemahkan otonomi artistik yang biasanya diasosiasikan dengan upaya kreatif seperti pembuat film. Hal ini merupakan isu perdebatan elitis-populis tentang isi media. Kaum elitis yang lebih menyukai daya kreatif ketimbangan pertimbangan komersial. Namun keyakinan populis tidak mempermasalahkan kekuatan pasar. Populis mengatakan bahwa jika suatu kreativitas film terganggu lantaran komersialisasi ini ikut campur tangan atas naskahnya, maka pembuat film pasti akan melakukan penyesuaian terhadap karya perfilman.

Jika komersialisasi dipandang akan mengganggu kualitas film, maka perlu adanya indikator yang terukur untuk menilai kualitas konten film Indonesia. Sebagai suatu seni, film tidak

\footnotetext{
${ }^{16}$ filmindonesia.or.id

https://www.google.com/search?q=placeme $\mathrm{nt}+$ dalam+film+indonesia\&source
} 
Tabel 1. Daftar Perusahaan Produksi Film Indonesia

\begin{tabular}{|l|l|l|l|}
\hline No & \multicolumn{3}{|c|}{ Perusahaan Produksi Film } \\
\hline 1 & 700 Pictures & 21 & Lenza Film \\
\hline 2 & Alenia Pictures & 22 & Maxima Pictures \\
\hline 3 & Amanah Surga Productions & 23 & MD Entertainment \\
\hline 4 & Barometer Lite & 24 & Miles Films \\
\hline 5 & Batavia Pictures & 25 & Mitra Pictures \\
\hline 6 & Dapur Film & 26 & Mizan Production \\
\hline 7 & Demi Gisela Citra Sinema & 27 & Movieglad Picture \\
\hline 8 & Diwangkara Film & 28 & Perfini \\
\hline 9 & E-Motion Entertainment & 29 & Prima Entertainment \\
\hline 10 & East Cinema & 30 & Rapi Films \\
\hline 11 & Falcon Pictures & 31 & Screenplay Productions \\
\hline 12 & Fourcolours Films & 32 & Sentra Mega Kreasi \\
\hline 13 & Frame Ritz & 33 & SinemArt \\
\hline 14 & Genta Buana Paramita & 34 & Soraya Intercine Films \\
\hline 15 & Indika Entertainment & 35 & Starvision \\
\hline 16 & Indika Pictures & 36 & Starvision Plus \\
\hline 17 & K2K Production & 37 & Studio X Producion \\
\hline 18 & Kalyana Shira Films & 38 & Timur Bumi Sinema \\
\hline 19 & Karnos Film & 39 & Tripar Multivision Plus \\
\hline 20 & Kepompong Gendut & 40 & Verona Pictures \\
\hline & & & \\
\hline
\end{tabular}

\section{Gambar 1. Haykal Kamil menjadi Official Merchandise}

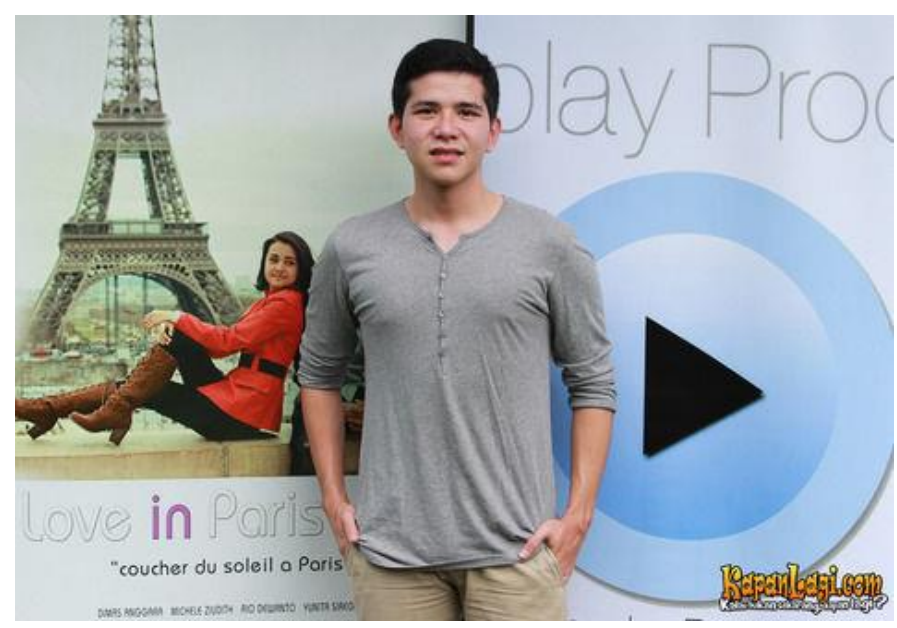


Euis Komalawati, Industri Film Indonesia :Membangun Keselarasan Ekonomi....

Tabel 2. Soundtrack Film Indonesia

\begin{tabular}{|l|l|l|l|}
\hline No & \multicolumn{1}{|c|}{ Judul lagu } & \multicolumn{1}{c|}{ Penyanyi } & \multicolumn{1}{c|}{ Film } \\
\hline 1 & Ada Apa Dengan Cinta & $\begin{array}{l}\text { Melly Goeslaw feat } \\
\text { Eric }\end{array}$ & Ada Apa Dengan Cinta \\
\hline 2 & My Heart & $\begin{array}{l}\text { Irwansyah feat Acha } \\
\text { Septriasa }\end{array}$ & Heart \\
\hline 3 & Ayat-Ayat Cinta & Rossa & Ayat-Ayat Cinta \\
\hline 4 & Jablay & Titi Kamal & Mendadak Dangdut \\
\hline 5 & Perahu Kertas & Maudy Ayunda & Perahu Kertas \\
\hline 6 & Cinta Sejati & Bunga Citra Lestari & Habibie Ainun \\
\hline 7 & Laskar Pelangi & Nidji & Laskar Pelangi \\
\hline 8 & Cahaya Bulan & So7 & Gie \\
\hline 9 & Dealova & Once & Dealova \\
\hline 10 & Garuda di Dadaku & Netral & Garuda Di Dadaku \\
\hline
\end{tabular}

Gambar 2. Gery Chocolatos dalam film Di Bawah Lindungan Ka'Bah

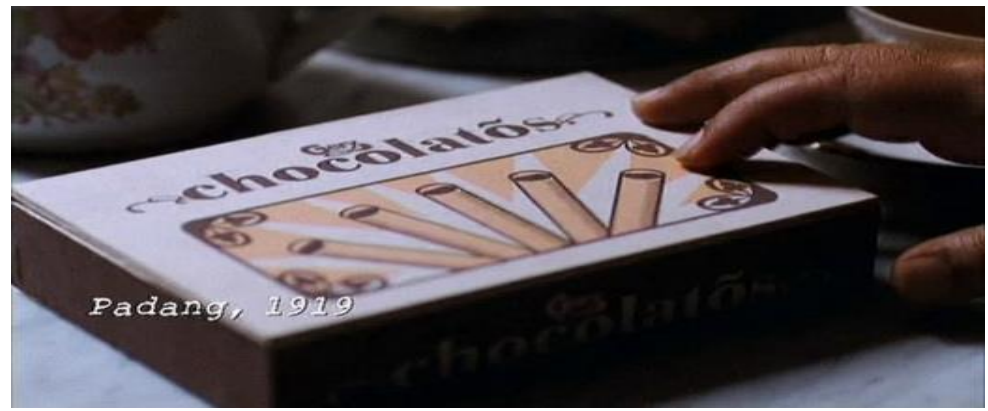

Gambar 3. Placement Product dalam film Habibie \& Ainun

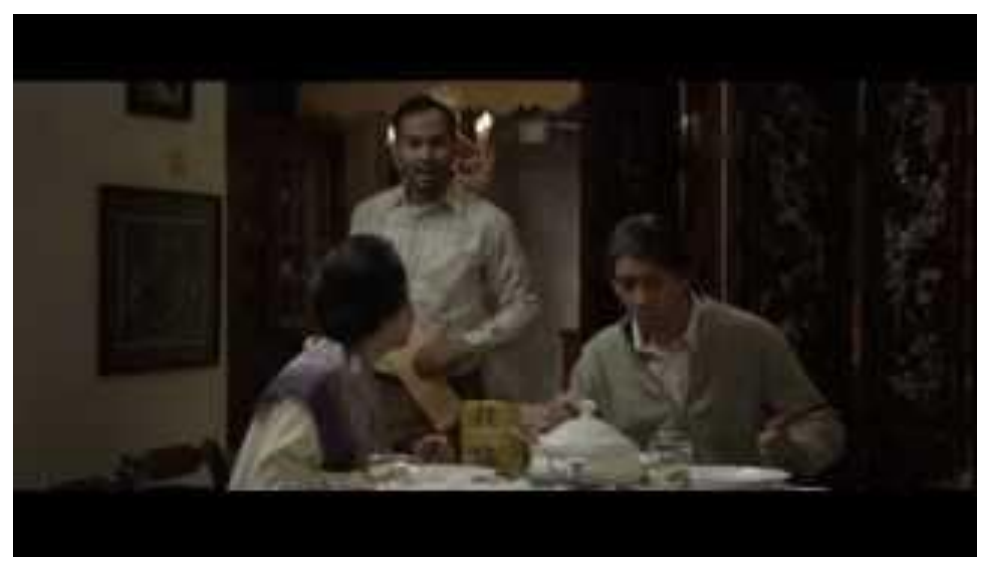


memiliki indikator baku terkait kualitas. Beberapa hal yang seringkali dijadikan tolak ukur kualitas film misalnya (1) film dengan tema yang baru dan menarik; (2) film dengan keunikannya ; (3) film yang mampu mempengaruhi penonton untuk larut dalam alur cerita; dan (4) film yang mendapat penghargaan. Untuk aspek keempat ini dengan asumsi film yang mendapat penghargaan telah melalui penilaian dari dewan juri dari berbagai kalangan dan mendapat pengakuan publik.

Jika dikaitkan dengan UU Nomor 33 tahun 2009 kualitas konten terdapat pada larangan konten film Indonesia yang diatur pada pasal 6 yakni Film yang menjadi unsur pokok kegiatan perfilman dan usaha perfilman dilarang mengandung isi yang : (a) mendorong khalayak umum melakukan kekerasan dan perjudian serta penyalahgunaan narkotika, psikotropika, dan zat adiktif lainnya; (b) menonjolkan pornografi; (c) memprovokasi terjadinya pertentangan antarkelompok, antarsuku, antar-ras, dan/atau antargolongan; (d) menistakan, melecehkan, dan/atau menodai nilainilai agama; (e) mendorong khalayak umum melakukan tindakan melawan hukum; dan/atau (f) merendahkan harkat dan martabat manusia ${ }^{18}$.

Festival-festival yang diselenggarakan pemerintah misalnya Festival Film Indonesia dan Apresiasi Film Indonesia telah melahirkan peraih penghargaan dari beragam kategori

\footnotetext{
${ }^{18}$ UU Nomor 33 Tahun 2009 tentang Perfilman.
}

dengan sistem penilaian dan penjurian yang cukup ketat. Namun sebagaimana umumnya di Indonesia, peraih penghargaan dalam ajang festival sering kali kurang mendapat tempat di industri perfilman yang sarat aspek komersial.

Festival Film Indonesia (FFI) merupakan ajang penghargaan tertinggi bagi dunia perfilman di Indonesia. FFI pertama kali diselenggarakan pada tahun 1955 dan berlanjut pada tahun 1960 dan 1967 (dengan nama Pekan Apresiasi Film Nasional), sebelum akhirnya mulai diselenggarakan secara teratur pada tahun 1973.

Di tahun 2016 FFI kembali digelar pada bulan November 2016 di Jakarta, menghasilkan pemenang untuk beragam kategori yakni : Lihat Tabel 3.

Dilihat dari para pemenang sebagian besar adalah judul film komersil yang ditayangkan di sinemasinema. Lima nominasi film terbaik antara lain Athirah, Rudy Habibie, Salawaku, Surat dari Praha, dan Aisyah Biarkan Kami Bersaudara. Muncul sebagai pemenang film terbaik tahun 2016 adalah Athirah. Sebelum Festival Film Indonesia 2016 digelar, ajang festival lain juga digelar oleh Kementerian Pendidikan dan Kebudayaan yakni Apresiasi Film Indonesia 2016, yang diselenggarakan di Manado pada bulan Oktober 2016. Lihat Gambar 4. 
Euis Komalawati, Industri Film Indonesia :Membangun Keselarasan Ekonomi....

Tabel 3. Daftar Pemenang dalam Festival Film Indonesia tahun 2016

\begin{tabular}{|c|c|c|}
\hline No & Kategori & Pemenang \\
\hline 1 & Sutradara Terbaik & $\begin{array}{l}\text { Riri Riza } \\
\text { ATHIRAH }\end{array}$ \\
\hline 2 & $\begin{array}{l}\text { Penulis Skenario Asli } \\
\text { Terbaik }\end{array}$ & $\begin{array}{l}\text { Jujur Prananto } \\
\text { (Aisyah, Biarkan Kami Bersaudara) }\end{array}$ \\
\hline 3 & $\begin{array}{l}\text { Penulis Skenario Adaptasi } \\
\text { Terbaik }\end{array}$ & $\begin{array}{l}\text { Salman Aristo dan Riri Riza } \\
\text { (Athirah) }\end{array}$ \\
\hline 4 & $\begin{array}{l}\text { Pengarah Sinematografi } \\
\text { Terbaik }\end{array}$ & $\begin{array}{l}\text { Faozan Rizal } \\
\text { (Salawaku) }\end{array}$ \\
\hline 5 & Pengarah Artistik Terbaik & $\begin{array}{l}\text { Eros Eflin } \\
\text { (Athirah) }\end{array}$ \\
\hline 6 & Penata Effek Visual Terbaik & $\begin{array}{l}\text { Andi Novianto } \\
\text { (Headshot) }\end{array}$ \\
\hline 7 & Penyunting Gambar Terbaik & $\begin{array}{l}\text { Wawan I. Wibowo } \\
\text { (My Stupid Boss) }\end{array}$ \\
\hline 8 & Penata Suara Terbaik & $\begin{array}{l}\text { Fajar Yuskemal, Aria Prayogi, dan M. } \\
\text { Ichsan Rachmaditta (Headshot) }\end{array}$ \\
\hline 9 & Penata Musik Terbaik & $\begin{array}{l}\text { Anto Hoed dan Melly Goeslaw } \\
\text { (Ada Apa dengan Cinta? 2) }\end{array}$ \\
\hline 10 & Perancang Busana Terbaik & $\begin{array}{l}\text { Chitra Subyakto } \\
\text { (Athirah) }\end{array}$ \\
\hline 11 & Pemeran Utama Pria Terbaik & $\begin{array}{l}\text { Reza Rahadian } \\
\text { (My Stupid Boss) }\end{array}$ \\
\hline 12 & $\begin{array}{l}\text { Pemeran Utama Wanita } \\
\text { Terbaik }\end{array}$ & $\begin{array}{l}\text { Cut Mini } \\
\text { (Athirah) }\end{array}$ \\
\hline 13 & $\begin{array}{l}\text { Pemeran Pendukung Pria } \\
\text { Terbaik }\end{array}$ & $\begin{array}{l}\text { Alex Abbad } \\
\text { (My Stupid Boss) }\end{array}$ \\
\hline 14 & $\begin{array}{l}\text { Pemeran Pendukung Wanita } \\
\text { Terbaik }\end{array}$ & $\begin{array}{l}\text { Raihaanun } \\
\text { (Salawaku) }\end{array}$ \\
\hline 15 & Pemeran Anak Terbaik & $\begin{array}{l}\text { Elko Kastanya } \\
\text { (Salawaku) }\end{array}$ \\
\hline 16 & Film Pendek Terbaik & $\begin{array}{l}\text { Prenjak } \\
\text { (Sutradara Wregas Bhanuteja; Produksi } \\
\text { Studio Batu) }\end{array}$ \\
\hline 17 & Film Animasi Terbaik & $\begin{array}{l}\text { Surat untuk Jakarta } \\
\text { (Sutradara Andre Sugianto, Aditya } \\
\text { Prabaswara, Ardhira Anugrah Putra; } \\
\text { Produksi Pijaru) }\end{array}$ \\
\hline 18 & Film Dokumensi Panjang & Gesang Sang Maestro Keroncong \\
\hline
\end{tabular}




\begin{tabular}{|c|c|c|}
\hline No & Kategori & Pemenang \\
\hline & Terbaik & $\begin{array}{l}\text { (Sutradara Marselli Sumarno; Produksi } \\
\text { Visinema) }\end{array}$ \\
\hline 19 & $\begin{array}{l}\text { Film Dokumenter Pendek } \\
\text { Terbaik }\end{array}$ & $\begin{array}{l}\text { Mama Amamapare } \\
\text { (Sutradara Yonri S. Revolt \& Febian } \\
\text { Kakisina; Produksi Eagle Institute } \\
\text { Indonesia). }\end{array}$ \\
\hline
\end{tabular}

\section{Gambar 4. Nominasi Film Terbaik FFI Tahun 2016}
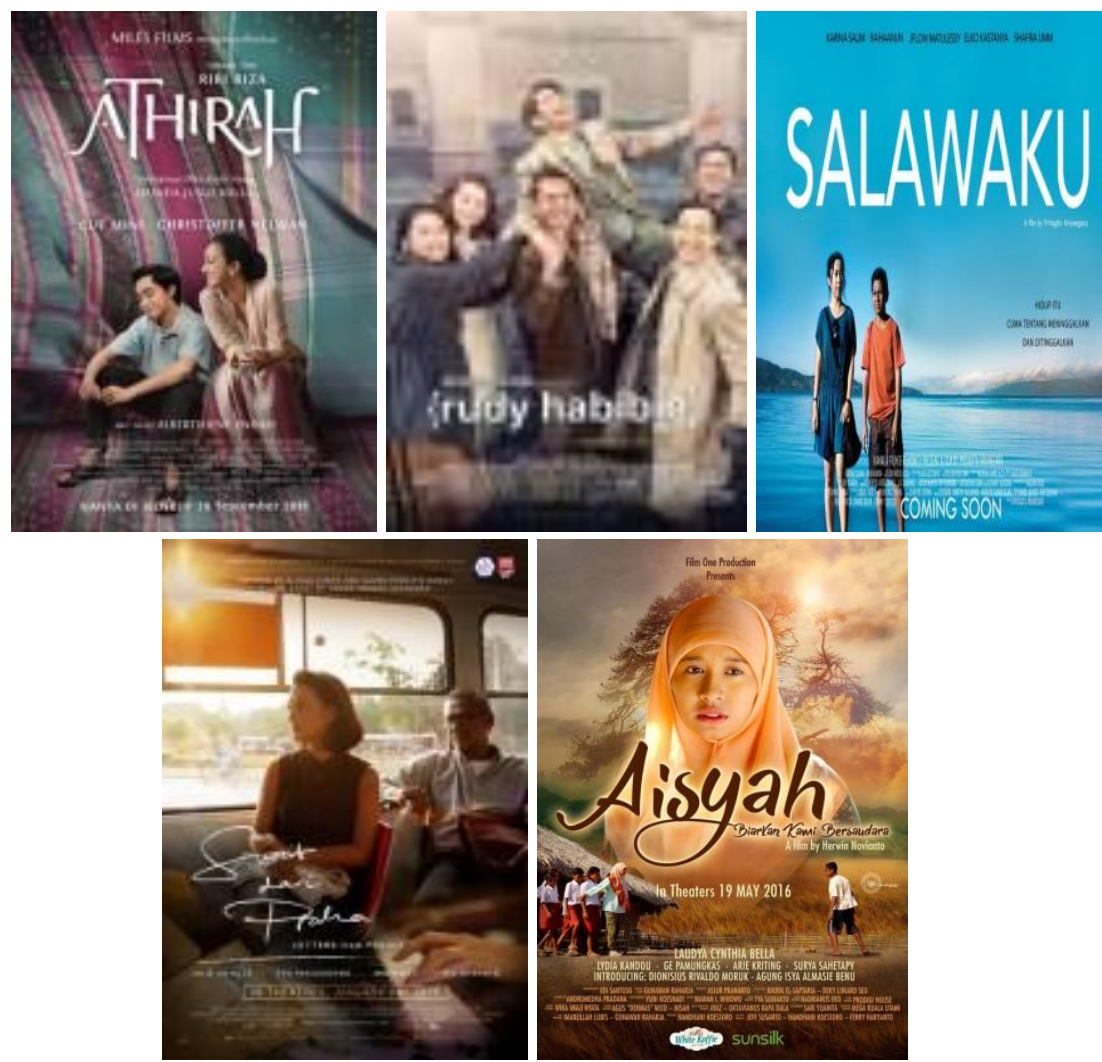

Apresiasi Film Indonesia (AFI) sendiri adalah penghargaan yang diberikan oleh Pusat Pengembangan Perfilman Kementerian Pendidikan dan Kebudayaan Republik Indonesia terhadap karya-karya film asli Indonesia yang sarat dengan pesan moral dan pendidikan ahlak bangsa. Apresiasi Film Indonesia (AFI) diberikan kepada insan film Indonesia, baik dari kalangan profesional, komunitas film, pelajar dan mahasiswa. $^{19}$

Berbeda dengan FFI, AFI menghadirkan pemenang yang lebih beragam dari aspek kategori. Berikut adalah daftar pemenang dalam Apresiasi Film Indonesia tahun 2016.

\footnotetext{
${ }^{19}$ http://www.aspirasinews.com/2016/10/inidaftar-lengkap-pemenang-apresiasi-filmindonesia-2016/
} 
Euis Komalawati, Industri Film Indonesia :Membangun Keselarasan Ekonomi....

Tabel 4. Daftar Pemenang Apresiasi Film Indonesia tahun 2016

\begin{tabular}{|l|l|l|}
\hline No & \multicolumn{1}{|c|}{ Kategori } & \multicolumn{1}{c|}{ Apresiasi } \\
\hline 1 & Fiksi Panjang Bioskop & Salawaku \\
\hline 2 & Fiksi Panjang Non Bioskop & Istirahatlah Kata-kata \\
\hline 3 & Fiksi Anak & Amarta \\
\hline 4 & $\begin{array}{l}\text { Fiksi Pendek Kategori } \\
\text { Umum }\end{array}$ & Pangreh \\
\hline 5 & Fiksi Pendek Pelajar & Ijinkan saya menikahinya \\
\hline 6 & $\begin{array}{l}\text { Dokumenter Kategori } \\
\text { Umum }\end{array}$ & Pantja Sila:Cita-cita \& Realita \\
\hline 7 & $\begin{array}{l}\text { Dokumenter Kategori } \\
\text { Pelajar }\end{array}$ & Kami Hanya Menjalankam Perintah,Jenderal ! \\
\hline 8 & Asosiasi & Asosiasi Produser Film Indonesia (APROFI) \\
\hline 9 & Pemerintah Daerah & DI.Yogyakarta \\
\hline 10 & Lembaga Pendidikan & Universitas Multimedia Nusantara,Serpong \\
\hline 11 & Komunitas Film & Sumbawa Cinema Society \\
\hline 12 & Festival Film & Jogja-Netpac Asian Film Festival \\
\hline 13 & Kritik Film & Hikmat Darmawan \\
\hline 14 & Program Film & Layar Perak (Program TV) \\
\hline 15 & Poster Film & Ada Apa Dengan Cinta 2 \\
\hline 16 & Adi Karya & Si Mamad \\
\hline 17 & Adi Insani & Hartanto \\
\hline 18 & Trailer Film & Ach...Aku Jatuh Cinta \\
\hline & &
\end{tabular}

Dalam daftar 15 Film Indonesia peringkat teratas dalam jumlah penonton tahun 2016, hanya beberapa film pemenang penghargaan festival yang masuk dalam daftar tersebut. Dengan data tersebut, nampak bahwa film yang dinilai berkualitas oleh dewan juri masih kurang mendapat perhatian dan apresiasi dari penonton. Namun yang menarik, selera penonton Indonesia tidak lagi didominasi film horor dan kekerasan, tetapi bergeser pada film-film komedi seperti Warkop DKI Reborn, Comic 8 : Kasino Kings part 2. Berikut adalah daftar 15 Film Indonesia peringkat teratas dalam perolehan jumlah penonton pada tahun 2016 berdasarkan tahun edar film. Lihat Tabel 5.

Sebagaimana dipaparkan Adorno, film adalah industri budaya yang bergerak dengan logika pasar, demikian pula industri perfilman di Indonesia. Perkembangan industri budaya film merupakan proses meningkatnya rasionalisasi dan konkritisasi (reification) masyarakat modern, dimana para sineas bergantung pada proses sosial yang bermuara pada ekonomi media. Industri film sepenuhnya dikomodifikasikan (commodified) melalui logika ekonomi 


\section{Tabel 5. Daftar 15 Film Indonesia Peringkat Teratas} dalam Jumlah Penonton tahun $2016^{20}$

\begin{tabular}{llr}
\hline \hline$\#$ & \multicolumn{1}{c}{ Judul } & Penonton \\
\hline \hline 1 & Warkop DKI Reborn: & 6.858 .616 \\
& Jangkrik Boss! part 1 & \\
2 & Ada Apa Dengan Cinta 2 & 3.665 .509 \\
3 & My Stupid Boss & 3.052 .657 \\
4 & Cek Toko Sebelah & 2.642 .957 \\
5 & Hangout & 2.620 .644 \\
6 & \{rudy habibie & 2.010 .072 \\
7 & Koala Kumal & 1.863 .541 \\
& Comic 8: Casino Kings & 1.835 .644 \\
& Part 2 & \\
9 & ILY from 38.000 Ft & 1.574 .576 \\
10 London Love Story & 1.124 .876 \\
11 Headshot & 732.763 \\
12 Sabtu Bersama Bapak & 639.530 \\
13 Bulan Terbelah di Langit & 582.487 \\
Amerika 2 & 567.917 \\
14 Talak 3 & 550.252 \\
15 The Doll & \\
\hline \hline
\end{tabular}

media. Sebagai industri padat modal, maka usaha pendukung dioptimalkan dengan placement product, merchandise tie ins yang sering kali pada akhirnya terkesan "dipaksakan".

Realitas sosial, fakta dan tema film diangkat dari kisah-kisah adaptasi novel yang telah lebih dulu dipasarkan. Dari kesuksesan suatu film, maka menginspirasi film-film lain dengan tema yang relatif sama. Kreativitas kurang dikembangkan, yang terjadi

20

http://filmindonesia.or.id/movie/viewer/2016\# produser memilih keputusan aman dari perhitungan bisnis agar tidak merugi di tengah biaya mahal pembuatan film. Pada akhirnya kebutuhan sudah ditakar (standardized). Penonton dibiasakan dengan tatanan sosial yang relatif terstandarisasi sehingga menciptakan keinginan (desire) terhadap objek-objek yang sama dan selera sama yang dihadirkan produser film.

\section{SIMPULAN DAN SARAN-SARAN}

\section{Simpulan}

1. Film sebagai media massa tumbuh dalam industri budaya yang padat modal. Tuntutan industri budaya menyebabkan komodifikasi realitas sosial dalam film. Akibat komodifikasi ini, kebutuhan dan tema-tema film terstandarisasi dengan keseragaman antara satu produser dengan lainnya hingga mengabaikan kreativitas seni. Selera yang tercipta dikelola dengan objek yang relatif sama dan publik tidak memiliki alternatif pilihan, karena industri film menghadirkan selera yang relatif seragam.

2. Film Indonesia yang dinilai memiliki kualitas berdasarkan penilaian dewan juri dalam berbagai ajang festival kurang mendapatkan perhatian publik karena terbatasnya ruang dan waktu untuk ekhibisi bagi film-film tersebut.

3. Film yang berkualitas dalam penilaian festival dapat masuk dalam industri film komersial dengan memperhatikan aspek ekonomi media serta menyelaraskan kualitas konten dan berupaya 
Euis Komalawati, Industri Film Indonesia :Membangun Keselarasan Ekonomi....

memperhatikan ekonomi media, karena tak dapat dipungkiri produksi, distribusi dan ekhibisi sebuah film membutuhkan modal yang tidak sedikit. Dengan demikian publik senantiasa teredukasi melalui film dengan konten berkualitas dan dapat menikmati dengan pilihan beragam di bioskop komersil.

\section{Saran}

1. Sebagaimana diamanatkan dalam UU nomor 33 tahun 2009, pemerintah turut bertanggung jawab dalam pengembangan perfilman di Indonesia, maka melalui Kementerian Pendidikan dan Kebudayaan, perlu mendukung industri kreatif film. Dukungan ini dapat dilakukan dengan membangun peraturan pemerintah yang mendukung baik dari proses produksi, distribusi, ekhibisi dan konsumsi media. Lembaga-lembaga seperti Badan Ekonomi Kreatif, Badan Perfilman Indonesia, yang telah dibangun perlu disinergikan untuk menghasilkan industri film yang kompetitif dengan memberikan perlindungan pada karya-karya anak bangsa. Dalam proses produksi, pemerintah dapat mendukung keberlanjutan perusahaan produksi film melalui pemberian insentif, proyek bersama, maupun bantuan finansial lainnya. Pada aspek distribusi dan ekshibisi, pemerintah harus mengembangkan perusahaan jaringan sinema tidak hanya dimonopoli oleh kelompok tertentu sehingga karya anak bangsa mendapatkan porsi yang seimbang dengan film-film import. Pada aspek konsumsi, publik harus diedukasi melalui literasi media yang tepat sehingga mencintai, menghargai dan bangga pada karya anak bangsa.

2. Perhatian pada industri film tidak berarti mengabaikan aspek kualitas sinema. Karenanya perlu meningkatkan SDM insan-insan kreatif agar memiliki kemampuan dan kompetensi kreatif menghasilkan karya seni yang berkualitas sekaligus diminati publik. Upaya ini dapat dilakukan dengan membuka lembaga pendidikan, pelatihan, mengembangkan workshop, diskusi dan memberikan ruang pada karyakarya independen.

\section{DAFTAR PUSTAKA}

Adorno, Theodore W \& Hokheimer, Max (1972). Dialectic of Enlightenment. New York : The Seabury Press.

Laporan Dialog Perfilman Nasional (2016). Peta Permasalahan Perfilman Nasional Dan Rekomendasi Program Dan Kebijakan Perfilman Nasional. Jakarta : Pusat Pengembangan Perfilman Indonesia.

Thompson, John B (1990). Ideology and Modern Culture - Critical Social Theory in The Era of Mass Communication. California : Stanford University Press.

$$
\text { (2015). Kritik }
$$
Ideologi Global - Teori Sosial 
Kritis tentang Relasi Ideologi dan Komunikasi Massa. Yogyakarta : IRCiSoD.

UU Nomor 33 Tahun 2009 tentang Perfilman.

Vivian, John (2008). The Media of Mass Communication 8th ed. Pearson Education.

\section{Internet}

http://afi2015.org/

http://filmindonesia.or.id/movie/viewer/ 2015 http://ppfindonesia.blogspot.co.id/p/tent ang-kami.html

http://www.merdeka.com/artis/haykalkamil-juga-jualan-officialmerchandise-love-in-paris-2.html http://www.muvila.com/film/artikel/pro duct-placement-paling-wajardalam-film-1302043-page3.html https://www.google.com/search?q=plac ement+dalam+film+indonesia\&so urce 